\title{
Experimental Design as a Tool for the Development of Citric Acid Production by Yarrowia lipolytica Using Glycerol as a Feedstock
}

\author{
Luana V. da Silva, Camila B. Tavares, Roberta dos R. Ribeiro, Fernando L. P. Pessoa, Maria Alice Z. Coelho and \\ Priscilla F. F. Amaral \\ Escola de Química/Universidade Federal do Rio de Janeiro, Centro de Tecnologia, Av. Athos da Silveira Ramos, 149, Bl. E, Cidade \\ Universitária, Rio de Janeiro 21949-900, Brazil
}

Received: May 14, 2013 / Published: August 20, 2013.

\begin{abstract}
Due to the scarcity of fossil fuels in the world, there is increasing interest in the commercial production of biodiesel, which leads to obtaining large amounts of glycerol as a byproduct. If not disposed of properly, glycerol can generate environmental impact. One of the promises, the application of the crude glycerol is the production of citric acid by microbial fermentation. Citric acid is industrially produced by a submerged fermentation process with Aspergillus niger, using sucrose as carbon source, but due to increased demand for citric acid, alternative processes using renewable sources or waste materials as substrates and the cultivation of yeast strains are being studied. The aim of the study was to determine the best culture condition for maximum citric acid synthesis and lower isocitric acid production from crude glycerol through experimental design tool. For this purpose, the yeast strain Yarrowia lipolytica IMUFRJ-50682 was cultivated in nitrogen-limited glycerol-based media. Therefore, glycerol and yeast extract concentrations and agitation speed were evaluated as independent variables. With pure glycerol, the highest citric acid production achieved was $16.5 \mathrm{~g} / \mathrm{L}$ with an isocitric acid production of $7.7 \%$ (in relation to citric acid). With crude glycerol, citric acid production reduced to $6.7 \mathrm{~g} / \mathrm{L}$ because of higher biomass yield. Therefore, an increase in the initial carbon to nitrogen molar ratio from 714 to 1,561 was necessary to increase citric acid production to $9.2 \mathrm{~g} / \mathrm{L}$, reducing isocitric acid production and to achieve a yield of $0.41 \mathrm{~g}$ of citric acid per glycerol consumed. In this condition, less nitrogen source was used, reducing production costs.
\end{abstract}

Key words: Yarrowia lipolytica, crude glycerol, media composition optimization, citric acid, experimental design.

\section{Introduction}

Citric acid (CA) is industrially produced by a submerged fermentation process with Aspergillus niger, using sucrose as carbon source [1]. The global annual production has increased to 1.7 million tons in 2007 as estimated by Business Communications Co. (http://www.bccresearch.com), which is greater than the production of any other organic acid obtained by fermentation process [2]. This market increases at a rate of $3.5 \%-4 \%$ per year, because CA is widely used in food, chemical and pharmaceutical industries due to its

\footnotetext{
Corresponding author: Priscilla F. F. Amaral, professor, research field: bioprocess engineering. E-mail: pamaral@eq.ufrj.br.
}

properties as an acidifier, preservative, $\mathrm{pH}$ adjuster, antioxidant and sequestrant. Although the conventional process for CA production is quite attractive, it is a complex and ecologically unsafe process due to the characteristics of the raw material used. Concentrated acids and alkali are used throughout the process, and the discharge into the environment (containing cyanide and gypsum) is comparable in amount to the product [3].

Due to increased demand for CA, alternative processes involving the cultivation of yeast strains are being studied, in order to achieve a cheaper and more efficient way to produce this commodity. Yarrowia lipolytica has a great potential to achieve this goal, since it produces CA from raw materials [4]. The 
starting point for this line of research was to gain access to n-paraffins and fatty acids that are not converted by A. niger as carbon sources [5]. Yarrowia lipolytica has been widely used for the production of organic acids through various renewable sources or waste materials as substrates, for example, glycerol from the production of biodiesel [6].

The obligatory industrial production of biodiesel has already resulted in the accumulation of high quantities of glycerol waste into the market, as the main by-product of transesterification process applied in biodiesel manufacture [7]. The bioconversion of glycerol can reduce the environmental impact caused by the biodiesel industry. Therefore, many microbial processes are being proposed to seek this by-product in its crude form [4, 8, 9]. An important way of raw glycerol valorisation is related to its biotransformation into CA [8].

The use of Yarrowia species presents several advantages in relation to filamentous fungi: higher tolerance to high substrate concentrations, higher yield, higher productivity and better process control because of the unicellular nature of yeasts [10]. One disadvantage is the significant amount of isocitric acid (ICA) produced during fermentation, which can reach levels of up to $50 \%$ of the total acid production thereby influencing CA yield negatively [11].

Papanikolaou et al. [6] produced 33-35 g of citric acid per liter after $236 \mathrm{~h}$ with high initial raw glycerol media $(80-120 \mathrm{~g} / \mathrm{L})$ in buffered medium containing ammonium sulfate and yeast extract $(0.5 \mathrm{~g} / \mathrm{L}$ of each). $Y$. lipolytica strains and three Candida strains were screened for CA production from pure glycerol by Levinson et al. [11]. Ammonium sulfate, yeast extract and thiamine hydrochloride were used as nitrogen sources. Y. lipolytica NRRL YB-423 was the best strain producing $21.6 \mathrm{~g}$ of citric acid/L in 10 days with a $54 \%$ yield. Rymowicz et al. [12] studied the simultaneous production of citric acid and erythritol under nitrogen-limited conditions with crude glycerol with an acetate negative mutant of $Y$. lipolytica Wratislavia K1 in fed-batch cultivations. Maximum citric acid production $(110 \mathrm{~g} / \mathrm{L})$ was obtained after $168 \mathrm{~h}$ of fed-batch cultivation with the initial glycerol concentration of $150 \mathrm{~g} / \mathrm{L}$. Y. lipolytica (IMUFRJ 50682) was studied for CA production using pure glycerol [13]. A production of $2.51 \mathrm{~g}$ of citric acid/L was obtained in non-buffered medium. A four times increase in CA production was obtained by using a buffer medium.

Although $Y$. lipolytica have been used to produce CA from crude glycerol by several researchers $[6,11$, 12], a study of the media composition optimization, regarding higher $\mathrm{CA}$ production as well as the reduction of ICA formation and input costs, is still lacking. Large amount of yeast extract and ammonium sulphate are still being used, which can increase the production costs. The purpose of the present investigation was to achieve the best medium composition, in relation to glycerol and yeast extract concentrations, and the best agitation speed to optimize CA production by Yarrowia lipolytica through experimental design technique. Pure and crude glycerol stemming from biodiesel industries were used as carbon sources.

\section{Materials and Methods}

\subsection{Microorganism}

Yarrowia lipolytica IMUFRJ 50682 selected from an estuary in Rio de Janeiro, Brazil and identified by the Institute of Microbiology at the Federal University of Rio de Janeiro, Brazil [14] was used for all experiments. The yeast strain was maintained on YPD-agar medium, containing $1 \%$ of yeast extract (Oxoid-Hampshire, UK), $2 \%$ of peptone from casein (Oxoid-Hampshire, UK), $2 \%$ of glucose (Reagen-RJ, Brazil) and 3\% of agar (Vetec-RJ, Brazil) in distilled water, and was stored at $4 \pm 1{ }^{\circ} \mathrm{C}$.

\subsection{Media and Culture Conditions}

Cells were cultivated in 0.51 Erlenmeyer flasks with 0.21 of YPD medium ( $\% \mathrm{w} / \mathrm{v}$ : yeast extract, 1 ; peptone, 2; and glucose, 2) on a rotary shaker (Tecnal Digimec 
BTC9090) at $28^{\circ} \mathrm{C}$ and $160 \mathrm{rpm}$ for $72 \mathrm{~h}$. The biomass produced was used to inoculate the CA production media (0.4 1 in 11 Erlenmeyer flask) in sufficient amount for a $1 \mathrm{~g}$ of cells (dry weight) per litre initial concentration.

CA production was performed in a rotary shaker (Tecnal Digimec BTC9090) at $28{ }^{\circ} \mathrm{C}$ for $96 \mathrm{~h}$. Agitation speed was studied. The media used contained (g/L): $\mathrm{KH}_{2} \mathrm{PO}_{4}: 12 ; \mathrm{Na}_{2} \mathrm{HPO}_{4}: 12 ; \mathrm{MgSO}_{4} \cdot 7 \mathrm{H}_{2} \mathrm{O}: 1.5$; $\mathrm{CaCl}_{2}: 0.15 ; \mathrm{FeCl}_{3} \cdot 6 \mathrm{H}_{2} \mathrm{O}: 0.15 ; \mathrm{ZnSO}_{4} \cdot 7 \mathrm{H}_{2} \mathrm{O}: 0.02$; $\mathrm{MnSO}_{4} \cdot \mathrm{H}_{2} \mathrm{O}: 0.06$. Yeast extract (nitrogen source) and glycerol (carbon source) concentrations in the CA production media were studied. Pure glycerol (Vetec, RJ, Brazil) and crude glycerine (obtained through the basic $(\mathrm{NaOH})$ transesterification soybean oil with ethanol and from the transesterification of soybean oil with methanol and potassium hydroxide by the research centre of Petrobras, RJ, Brazil) were evaluated.

\subsection{Crude Glycerin Pretreatment}

The $\mathrm{pH}$ of crude glycerin was adjusted with $\mathrm{H}_{2} \mathrm{SO}_{4}$ $(1 \mathrm{~N})$ to the range of 6-7 in order to eliminate free alkalinity. After that, it was heated $\left(120^{\circ} \mathrm{C}\right)$ for $1 \mathrm{~h}$ for ethanol elimination. The sulphate produced by the neutralization was separated by decantation in a separation funnel for $24 \mathrm{~h}$.

\subsection{Experimental Design}

Initially pure glycerol was used as sole carbon source to assess the metabolic behavior of the strain Yarrowia lipolytica IMUFRJ 50682 and the effect of media composition in CA production.

A complete $2^{k}$ factorial design, with $k=3$ and two replicates at the central points, was carried out in order to identify the parameters with a significant effect on CA production. Pure glycerol and yeast extract concentrations were adopted as independent variables and the maximum citric acid production $\left(P_{C A}\right)$ was taken as the dependent variable of the experimental design. Glycerol and yeast extract concentrations ranges were $30 \mathrm{~g} / \mathrm{L}$ to $50 \mathrm{~g} / \mathrm{L}$ and $0.1 \mathrm{~g} / \mathrm{L}$ to $0.9 \mathrm{~g} / \mathrm{L}$, respectively. The agitation ranged from $160 \mathrm{rpm}$ to 250 rpm. The software statistic (version 7.0) was used for regression and graphical analyses of the data obtained.

Glycerol, yeast extract concentrations and agitation speed for the other experimental designs were selected after the results and, therefore, are described in the text.

Once the variables having the statistically significant influence on the responses were identified, a central composite design (CCD) was used to optimize the levels of these variables. The $2^{2}$ factorial design was used, consisting of four assays $(-1$ and +1$)$, two center points and four axial points $(-1.41$ and +1.41$)$, and resulted in a total of 10 experiments.

\subsection{Analytical Methods}

Biomass concentration was determined in spectrophotometer (Hach DR/4000 UV-VIS) by optical density measurements at $570 \mathrm{~nm}$ and these values were converted to $\mathrm{mg}$ dry weigh (d.w.) cells $/ \mathrm{mL}$ using a conversion factor previously established by the curve of dry weight.

Samples from the CA production medium free of cells were used for the analysis of organic acids, glycerol and $\mathrm{pH}$.

The concentration of CA and ICA were determined in this cell-free sample by enzymatic kit (R-Biopharm/Boehringer Mannhein/Roche).

Glycerol was quantified by enzymatic-colorimetric method for the quantification of triglycerides (LABORLAB Kit for triglycerides) and $\mathrm{pH}$ of culture medium free of cells was determined using a $\mathrm{pH}$ meter Digimed brand, model DM-22.

\subsection{Fermentation Parameters}

For comparison between all trials, production parameters were determined.

Mass yield of $C A$ from glycerol consumed $\left(Y_{C A / G}\right)$, was calculated from:

$$
Y_{C A / G}=-\frac{P_{C A}}{G_{f}-G_{i}}(\mathrm{~g} / \mathrm{g})
$$


Biomass yield from glycerol consumed $\left(Y_{X / G}\right)$, was calculated from:

$$
Y_{X / G}=-\frac{X_{f}-X_{i}}{G_{f}-G_{i}} \quad(\mathrm{~g} / \mathrm{g})
$$

Volumetric citric acid productivity $\left(Q_{C A}\right)$, was calculated from:

$$
Q_{C A}=\frac{P_{C A}}{V^{*} t}(\mathrm{~g} /(\mathrm{L} \mathrm{h}))
$$

Mass ratio between $\mathrm{CA}$ and ICA $\left(R_{C A / I C A}\right)$, was calculated from:

$$
R_{C A / I C A}=\frac{P_{C A}}{P_{I C A}}
$$

where, indices $i$ and $f$ correspond to the initial and final (at the time of maximum CA concentration) quantity of elements, respectively; $G$ : Glycerol concentration; $X$ : cell concentration; $t$ : time of fermentation of citric acid maximum production; $V$ : initial volume of liquid culture

\section{Results and Discussion}

In literature, no publication has been traced on optimization of culture medium together with system agitation to maximize CA production by Yarrowia lipolytica with glycerol as the carbon source. In preliminary trials, growth and CA production by $Y$. lipolytica IMUFRJ 50682 were studied in pure glycerol.
From the best result, crude glycerol was used and a new optimization was performed.

\subsection{CA Production with Pure Glycerol}

Identification of the parameters influencing CA production.

In a previous work [13], Y. lipolytica IMUFRJ 50682 produced higher $\mathrm{CA}$ concentrations in a buffered medium without ammonium sulphate and, therefore, these conditions were established here. It has also been reported that when sugars or glycerol are used as substrates, production of CA is induced by exhaustion of nitrogen source from the medium $[6,15]$. Therefore, pure glycerol and yeast extract concentrations were first studied in a full factorial experimental design (FFD). Agitation speed was also considered in these trials. Table 1 shows the experimental design matrix and the results for CA production.

In this set of experiments, the maximum CA produced ranged from $0.68 \mathrm{~g} / \mathrm{L}$ to $14.04 \mathrm{~g} / \mathrm{L}$. It is worth mentioning that the difference between these values is much larger than the variation between the results of the center points. This shows reproducibility of the experiments, indicating that the observed variations in the $P_{C A}$ values are due to differences in the independent variables.

\begin{tabular}{|c|c|c|c|c|c|c|c|c|}
\hline Run & $\begin{array}{l}\text { Glycerol } \\
(\mathrm{g} / \mathrm{L})\end{array}$ & $\begin{array}{l}\text { Yeast extract } \\
(\mathrm{g} / \mathrm{L})\end{array}$ & $\begin{array}{l}\text { Agitation } \\
\text { speed (rpm) }\end{array}$ & $C / N^{\mathrm{a}}$ & $\begin{array}{l}P_{C A}{ }^{\mathrm{b}} \\
(\mathrm{g} / \mathrm{L})\end{array}$ & $\begin{array}{l}X_{\operatorname{Max}}^{\mathrm{c}} \\
\text { (g d.w./L) }\end{array}$ & $\begin{array}{l}Y_{C A / G}^{\mathrm{d}} \\
(\mathrm{g} / \mathrm{g})\end{array}$ & $\begin{array}{l}Q_{C A}{ }^{\mathrm{e}} \\
(\mathrm{g} /(\mathrm{L} \mathrm{h}))\end{array}$ \\
\hline 1 & $-1(30)$ & $-1(0.1)$ & $-1(160)$ & 1,260 & $1.67(80 \mathrm{~h})$ & 6.40 & 0.56 & 0.02 \\
\hline 2 & $+1(50)$ & $-1(0.1)$ & $-1(160)$ & 2,098 & $1.46(94 \mathrm{~h})$ & 6.82 & 0.03 & 0.02 \\
\hline 3 & $-1(30)$ & $+1(0.9)$ & $-1(160)$ & 144 & $0.69(101 \mathrm{~h})$ & 7.61 & 0.23 & 0.01 \\
\hline 4 & $+1(50)$ & $+1(0.9)$ & $-1(160)$ & 237 & $0.68(80 \mathrm{~h})$ & 5.76 & 0.01 & 0.01 \\
\hline 5 & $-1(30)$ & $-1(0.1)$ & $+1(250)$ & 1,260 & $14.04(93 \mathrm{~h})$ & 4.44 & 0.47 & 0.15 \\
\hline 6 & $+1(50)$ & $-1(0.1)$ & $+1(250)$ & 2,098 & $11.40(93 \mathrm{~h})$ & 4.73 & 0.23 & 0.12 \\
\hline 7 & $-1(30)$ & $+1(0.9)$ & $+1(250)$ & 144 & $7.89(93 \mathrm{~h})$ & 7.04 & 0.26 & 0.08 \\
\hline 8 & $+1(50)$ & $+1(0.9)$ & $+1(250)$ & 237 & $6.35(93 \mathrm{~h})$ & 7.44 & 0.13 & 0.07 \\
\hline 9 & $0(40)$ & $0(0.5)$ & $0(205)$ & 339 & $4.69(96 \mathrm{~h})$ & 8.81 & 0.12 & 0.05 \\
\hline 10 & $0(40)$ & $0(0.5)$ & $0(205)$ & 339 & $4.91(88 \mathrm{~h})$ & ND & 0.12 & 0.05 \\
\hline
\end{tabular}

Table 1 Coded levels and real values (in parentheses) of the $2^{3}$ full factorial design (FFD) and citric acid (CA) production parameters for trials with pure glycerol.

${ }^{\mathrm{a}} C / N$ : carbon to nitrogen molar ratio in the beginning of the experiment;

${ }^{\mathrm{b}} P_{C A}$ : maximum citric acid production, the time when it was obtained (in parenthesis);

${ }^{\mathrm{c}} X_{\text {Max }}$ : maximum biomass obtained;

${ }^{\mathrm{d}} Y_{C A / G}$ : mass yield of CA from glycerol consumed;

${ }^{\mathrm{e}} Q_{C A}$ : volumetric citric acid productivity. 
The best results for $\mathrm{CA}$ concentration were obtained in experimental run 5 and 6 , i.e., when lower yeast extract concentration and major agitation speed were used. In those experiments, highest citric acid yield $\left(Y_{C A / G}\right)$ and productivity $\left(Q_{C A}\right)$ were also obtained (Table 1). Tests 5 and 6 differ only by the initial concentration of glycerol, establishing initial $\mathrm{C} / \mathrm{N}$ molar ratio of 1,217 and 2,028, respectively. The ICA concentration detected when higher $\mathrm{CA}$ was produced in test 5 was $1.89 \mathrm{~g} / \mathrm{L}$, with a $R_{C A} / I C A$ of 7.43 .

Several studies in literature report the effect of high initial $C / N$ molar ratio in high $\mathrm{CA}$ production by microorganisms. However, all tests that were performed with lower levels of agitation speed presented lower CA production (Table 1), including high initial $C / N$ molar ratio tests. Rywińska et al. [16] have also shown that the availability of oxygen to the microorganisms is essential to increase CA production. Table 1 is possible to notice that the agitation speed had more influence in CA production than the initial $C / N$ molar ratio and the highest $\mathrm{CA}$ production was not obtained when higher initial $C / N$ molar ratio was used (Table 1). However, runs 7 and 8, performed at 250 rpm (higher agitation speed), yielded half the CA concentration than runs 5 and 6 and promoted higher cell growth $\left(X_{\max }\right)$, indicating that low initial $C / N$ molar ratio is not good for this process.

The Pareto diagram in Fig. 1 shows the agitation speed as the variable with greater effect on the response variable $(\alpha=95 \%)$, followed by the yeast extract concentration. These variables had opposite effects: the agitation speed had a positive effect and the yeast extract concentration had a negative effect. The results show that the dependent variable was not affected by glycerol concentration in the range studied. The interaction between yeast extract and agitation showed a statistically significant negative effect on the CA production.

\subsection{Central Composite Rotatable Design}

Based on the results of the $2^{3}$ FFD, a more detailed study of the influence of yeast extract and the agitation speed was performed by a central composite rotatable design (CCRD) $2^{2}$. Glycerol initial concentration was set at $30 \mathrm{~g} / \mathrm{L}$ as it was not statistically significant in the first set of experiments. Yeast extract concentration

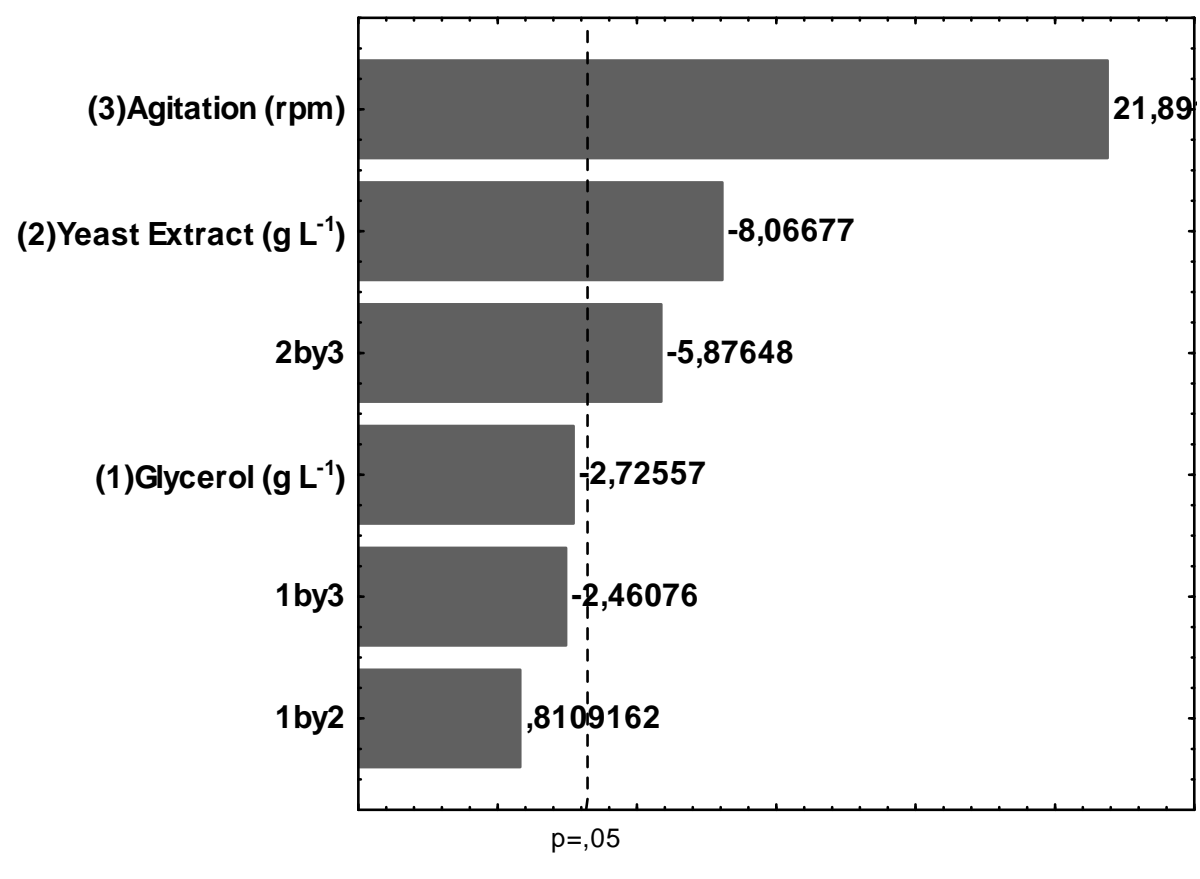

Standardized Effect Estimate (Absolute Value)

Fig. 1 Pareto diagram for the estimated effect of each variable of the $2^{3}$ full factorial design (FFD). Dependent variable: citric acid production (g/L). 
and agitation speed levels were also chosen by the results the FFD, fixing the best conditions at the center point $(0.1 \mathrm{~g} / \mathrm{L}$ of yeast extract and $250 \mathrm{rpm}$ of agitation speed). The complete design matrix of the experiments used and the CA produced are shown in Table 2. CA production was relatively high for all experimental runs in this second factorial design and the highest result was obtained for run 8 .

Fig. 2 shows that linear and first-order effects and interactions of variables are not statistically significant in the $95 \%$ confidence interval. The value of the coefficient of determination was low $(60 \%)$. Therefore, it was not possible to perform statistical analysis and to obtain a mathematical model. Despite of that, it seems that an optimum working range was found, with good results for production, productivity, substrate conversion $\left(Y_{C A / G}\right)$ and less ICA production.

It can be seen (Table 2) that the highest CA production was obtained when smaller initial $C / N$ molar ratio was used. However, the $C / N$ molar ratio range (714 to 4,262$)$ was larger than the difference between CA production $(9.4 \mathrm{~g} / \mathrm{L}$ to $16.5 \mathrm{~g} / \mathrm{L})$ indicating that when a high $\mathrm{C} / \mathrm{N}$ molar ratio is used (above 700), it does not influence much CA production. Levinson et al. [11] verified that when higher initial nitrogen concentrations ( $C / N$ molar ratio under 172) were used for Y. lipolytica NRRL YB-423, CA was utilized as substrate as incubation progressed and $\mathrm{C} / \mathrm{N}$ molar ratios from 343 to 1,714 promoted CA production between $15 \mathrm{~g} / \mathrm{L}$ and $21 \mathrm{~g} / \mathrm{L}$ in more than $200 \mathrm{~h}$ of process.

The production of ICA was very low, which resulted in a maximum $R_{C A / I C A}$ of 14 (Table 2). There is not many works in literature concerning the concomitant production of CA and ICA. For Y. lipolytica NRRL YB-423, the top $R_{C A / I C A}$, when glycerol was used, was $11.3[11]$.

\subsection{CA Production with Crude Glycerol from Biodiesel Production}

The experimental conditions of run 8 (Table 2) were chosen as reference to test the use of crude glycerol. When glycerine obtained from the transesterification of soybean oil with ethanol and sodium hydroxide was used ( $81 \%$ of purity), CA production reduced from $16.5 \mathrm{~g} / \mathrm{L}$ to $6.7 \mathrm{~g} / \mathrm{L}$ and the productivity decreased from $0.17 \mathrm{~g} /(\mathrm{L} \mathrm{h})$ to $0.07 \mathrm{~g} /(\mathrm{L} \mathrm{h})$ in comparison to pure glycerol. At this point the $R_{C A / I C A}$ was also lower (4.3 instead of 12.0). Fig. 3 presents the kinetics of both cultures, with pure and crude glycerol (Figs. 3a and 3b).

Table 2 Coded levels and real values (in parentheses) of the central composite design (CCD) and citric acid (CA) production parameters for trials with $30 \mathrm{~g} / \mathrm{L}$ of pure glycerol.

\begin{tabular}{llllllll}
\hline Run & $\begin{array}{l}\text { Yeast extract } \\
(\mathrm{g} / \mathrm{L})\end{array}$ & $\begin{array}{l}\text { Agitation } \\
\text { speed }(\mathrm{rpm})\end{array}$ & $C / N^{\mathrm{a}}$ & $\begin{array}{l}P_{C A} \mathrm{~b} \\
(\mathrm{~g} / \mathrm{L})\end{array}$ & $R_{C A / C A}{ }^{\mathrm{c}}$ & $\begin{array}{l}Y_{C A / G}{ }^{\mathrm{d}} \\
(\mathrm{g} / \mathrm{g})\end{array}$ & $\begin{array}{l}Q_{C A}{ }^{\mathrm{e}} \\
(\mathrm{g} /(\mathrm{L} h))\end{array}$ \\
\hline 1 & $-1(0.0500)$ & $-1(210.0)$ & 2516 & $12.29(88 \mathrm{~h})$ & 14.1 & 0.41 & 0.14 \\
2 & $1(0.1500)$ & $-1(210.0)$ & 842 & $11.95(88 \mathrm{~h})$ & 13.6 & 0.40 & 0.14 \\
3 & $-1(0.0500)$ & $1(290.0)$ & 2516 & $9.43(88 \mathrm{~h})$ & 10.7 & 0.31 & 0.11 \\
4 & $1(0.1500)$ & $1(290.0)$ & 842 & $12.10(93 \mathrm{~h})$ & 11.7 & 0.40 & 0.13 \\
5 & $0(0.1000)$ & $0(250.0)$ & 1260 & $9.51(93 \mathrm{~h})$ & 9.2 & 0.32 & 0.10 \\
6 & $0(0.1000)$ & $0(250.0)$ & 1260 & $10.38(93 \mathrm{~h})$ & 9.1 & 0.35 & 0.11 \\
7 & $-1.41(0.0295)$ & $0(250.0)$ & 4262 & $12.84(94 \mathrm{~h})$ & 11.7 & 0.43 & 0.14 \\
8 & $+1.41(0.1705)$ & $0(250.0)$ & 741 & $16.49(94 \mathrm{~h})$ & 12.0 & 0.55 & 0.17 \\
9 & $0(0.1000)$ & $-1.41(193.6)$ & 1260 & $10.67(94 \mathrm{~h})$ & 8.9 & 0.36 & 0.11 \\
10 & $0(0.1000)$ & $1.41(306.4)$ & 1260 & $13.91(99 \mathrm{~h})$ & 10.2 & 0.46 & 0.14 \\
\hline
\end{tabular}

${ }^{\mathrm{a} C} \mathrm{C} N$ : carbon to nitrogen molar ratio in the beginning of the experiment;

${ }^{\mathrm{b}} P_{C A}$ : maximum citric acid production, the time when it was obtained (in parenthesis);

${ }^{\mathrm{c}} R_{C A / I C A}$ : mass ratio between CA and ICA;

${ }^{\mathrm{d}} Y_{C A / G}$ : mass yield of CA from glycerol consumed;

${ }^{\mathrm{e}} \mathrm{Q}_{\mathrm{CA}}$ : volumetric citric acid productivity. 


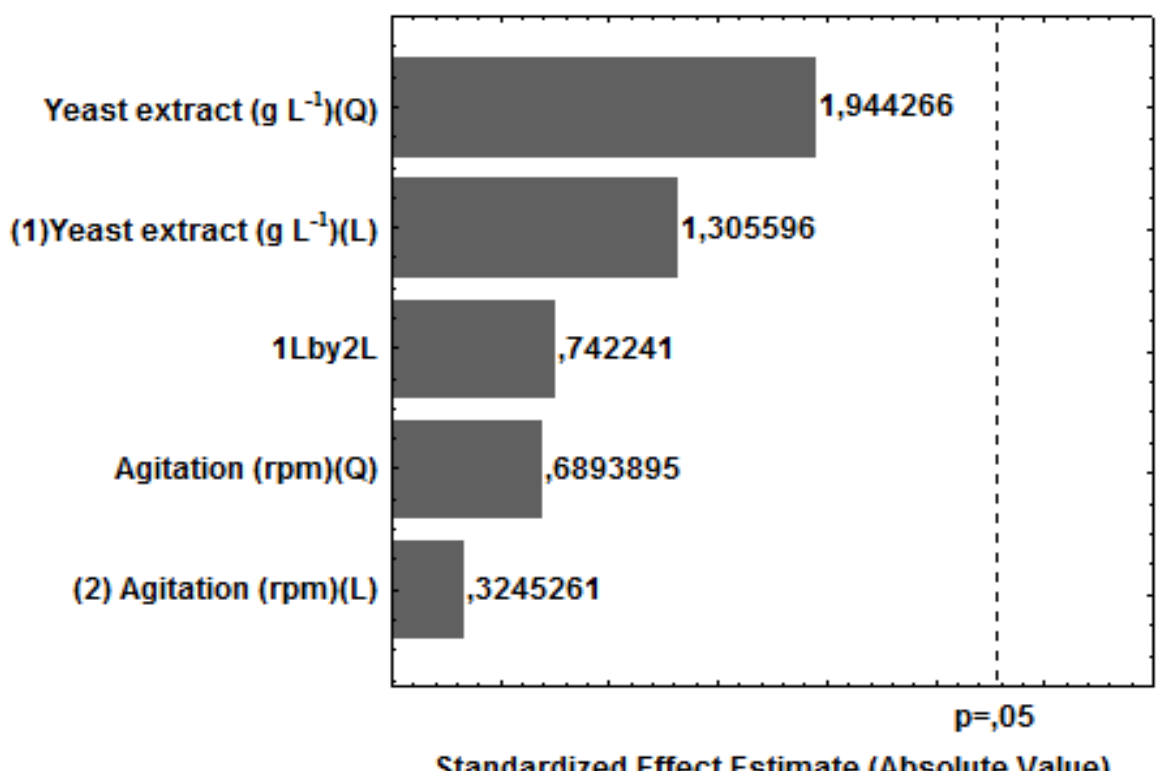

Fig. 2 Pareto diagram for the estimated effect of each variable of the central composite design (CCD) with pure glycerol. Dependent variable: citric acid production (g/L).

It can be seen that cell growth was much higher in crude glycerol, which might happen because of the presence of oil residues present in this raw material and this yeast capability to use it as an additional substrate [17]. This fact has influenced the reduction on CA production since it diverted the metabolism to cell growth. The $\mathrm{pH}$ reduction was similar in those cases, especially because a buffered medium was used.

Another source of crude glycerol was tested (glycerine obtained from the transesterification of soybean oil with methanol and potassium hydroxide, $83 \%$ of purity) in the same conditions of the experimental run $8(30 \mathrm{~g} / \mathrm{L}$ glycerol, $0.1705 \mathrm{~g} / \mathrm{L}$ yeast extract and $250 \mathrm{rpm})$. Biomass production was still higher than with pure glycerol $\left(X_{\max }=5.0 \mathrm{~g} / \mathrm{L}\right)$ and CA production $(4.35 \mathrm{~g} / \mathrm{L})$ was even inferior to the other crude glycerol tested. It is very clear that the impurities present in crude glycerol influence CA production. It is possible that methanol residues are harmful to biomass and interfered also with CA production. Papanikolaou et al. [6] tested crude glycerol for CA production, obtained higher values $(11.9 \mathrm{~g} / \mathrm{L})$, but used higher yeast extract concentration $(0.5 \mathrm{~g} / \mathrm{L})$. Different yeast extract concentrations were tested with this crude glycerol in order verify if other $C / N$ molar ratios could improve $\mathrm{CA}$ production and the results are present in Fig. 4. It depicts that ICA production was induced and increase or decrease in yeast extract concentration did not improve CA production.

\subsection{CA Production Optimization with Crude Glycerol}

By the results with pure glycerol and the test with crude glycerol, an experimental design was assembled. Glycerol concentration was again included because it influences on the amount of crude glycerol used and its residues could affect CA production. Therefore, a central composite rotatable design, $2^{k}$, with $k=2$, two center points and four axial points, was used to optimize the best medium composition. The agitation speed was kept constant at $250 \mathrm{rpm}$ as indicated by the study with pure glycerol. Crude glycerol from the transesterification of soybean oil with ethanol and sodium hydroxide was used.

It is possible to observe in Table 3 that CA production varied from $5.50 \mathrm{~g} / \mathrm{L}$ to $9.22 \mathrm{~g} / \mathrm{L}$, with the experimental design adopted. Through the change in medium composition, the $\mathrm{CA}$ production and its volumetric productivity reached $9.22 \mathrm{~g} / \mathrm{L}$ and $0.10 \mathrm{~g} /(\mathrm{L}$ h), respectively, for the trial with $45 \mathrm{~g} / \mathrm{L}$ of glycerol and $0.1 \mathrm{~g} / \mathrm{L}$ of yeast extract (Run 2). 


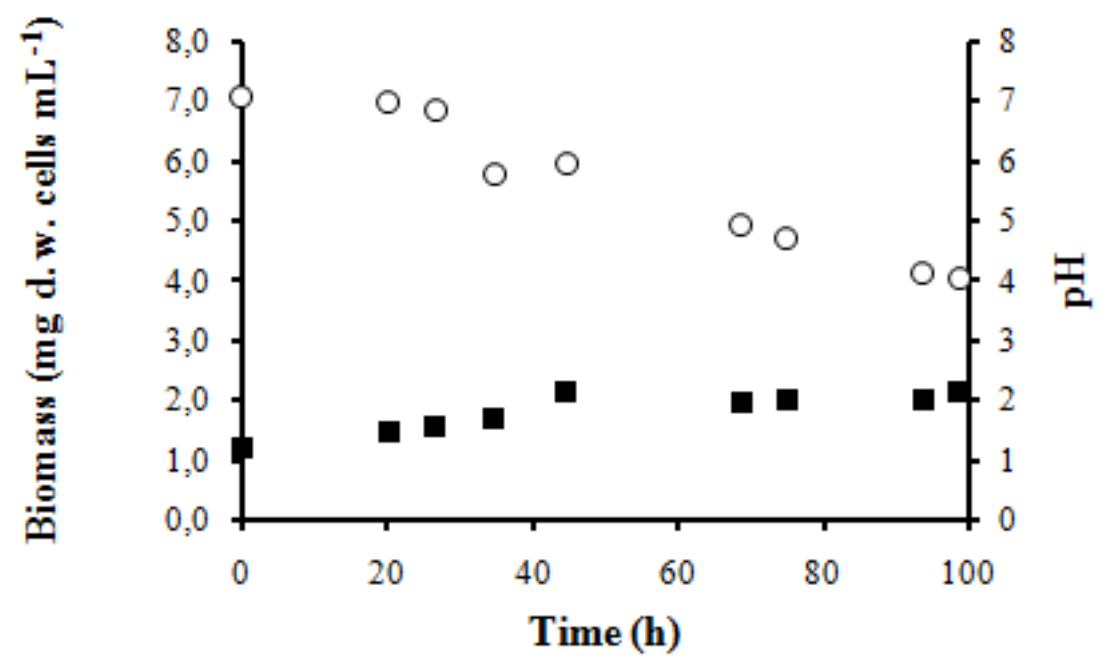

\section{- Biomass ${ }^{\circ} \mathbf{p H}$}

(a) Pure glycerol

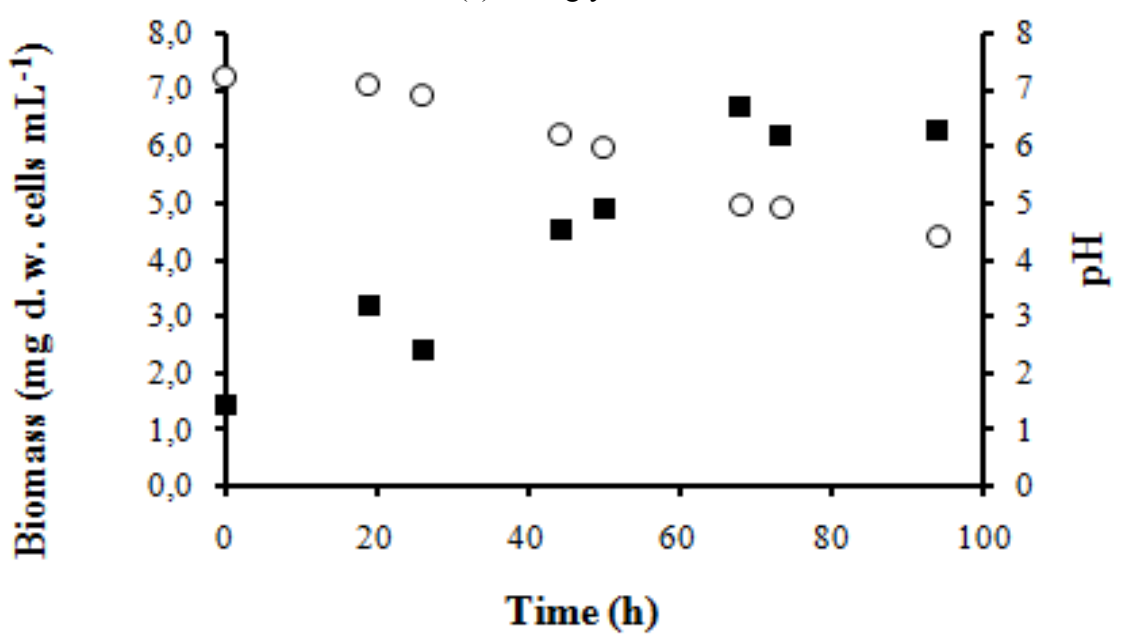

\section{- Biomass ○pH}

(b) Crude glycerol

Fig. 3 Cell growth and pH kinetics of Yarrowia lipolytica IMUFRJ 50682 cultivated at $250 \mathrm{rpm}$ with 0.1705 g/L of yeast extract and $30 \mathrm{~g} / \mathrm{L}$ glycerol.

Analysing the results shown in Table 3, it is possible to observe that $C / N$ molar ratio does not influence much CA production when crude glycerol is used, with opposite effects (Runs 2 and 3) resulting in the same CA production, productivity and yield.

Through analysis of the Pareto diagram (Fig. 5), it was observed that the effects of independent variables were not statistically significant at $95 \%$ confidence interval in the studied ranges. Therefore, it was not possible to obtain a mathematical model and to perform statistical analysis, just to identify one best condition.
Despite the fact that the conditions of Runs 2 and 3 favored the same CA production and productivity, Run 2 was performed with less yeast extract, which would be the major cost of the culture medium.

In these trials (Table 3), cell growth was inhibited in the most cases as $X_{\max }$ obtained for the first trial with crude glycerol (6.7 g d.w./L) was superior than most of the values obtained, specially Run 2 (4.3 g d.w./L). Therefore, the increase in $C / N$ molar ratio was necessary to divert the carbon flux to $\mathrm{CA}$ production. However, when less biomass is present, less product is 


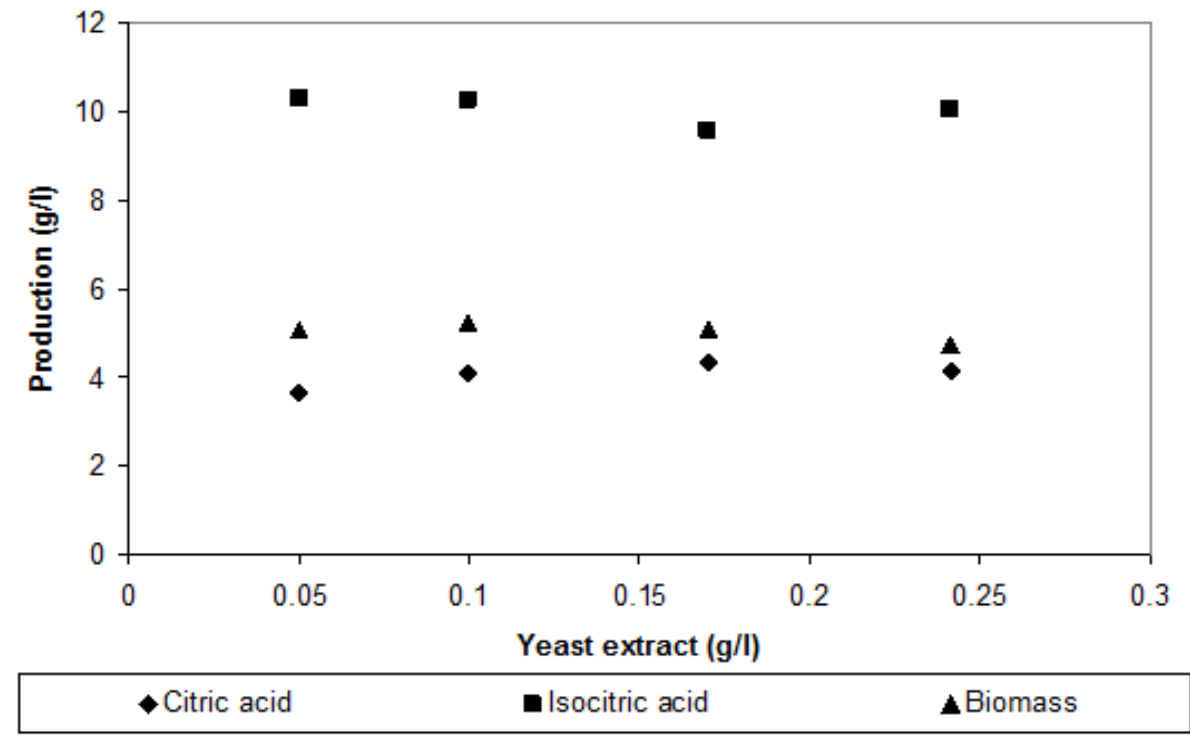

Fig. 4 Biomass, citric and isocitric acids production by Yarrowia lipolytica IMUFRJ 50682 cultivated at $250 \mathrm{rpm}$ with $30 \mathrm{~g} / \mathrm{L}$ crude glycerol (from the transesterification of soybean oil with methanol and potassium hydroxide) and different yeast extract concentrations.

Table 3 Coded levels and real values (in parentheses) of the central composite design (CCD) and citric acid (CA) production parameters for trials with crude glycerol.

\begin{tabular}{lllllllll}
\hline Run & $\begin{array}{l}\text { Glycerol } \\
(\mathrm{g} / \mathrm{L})\end{array}$ & $\begin{array}{l}\text { Yeast Extract } \\
\mathrm{g} / \mathrm{L})\end{array}$ & $C / N^{\mathrm{a}}$ & $\begin{array}{l}P_{C A}{ }^{\mathrm{b}} \\
\mathrm{g} / \mathrm{L})\end{array}$ & $\begin{array}{l}X_{M a x}{ }^{\mathrm{c}} \\
(\mathrm{g} \mathrm{d} . \mathrm{w} . / \mathrm{L})\end{array}$ & $R_{C A / I C A}{ }^{\mathrm{d}}$ & $\begin{array}{l}Y_{C A / G}{ }^{\mathrm{e}} \\
(\mathrm{g} / \mathrm{g})\end{array}$ & $\begin{array}{l}Q_{C A}{ }^{\mathrm{f}} \\
(\mathrm{g} /(\mathrm{L} \mathrm{h}))\end{array}$ \\
\hline 1 & $-1(35.00)$ & $-1(0.1000)$ & 1,180 & 7.72 & 5.26 & 6.8 & 0.33 & 0.08 \\
2 & $1(45.00)$ & $-1(0.1000)$ & 1,516 & 9.22 & 4.34 & 10.4 & 0.41 & 0.10 \\
3 & $-1(35.00)$ & $1(0.2410)$ & 490 & 9.11 & 5.72 & 7.7 & 0.42 & 0.10 \\
4 & $1(45.00)$ & $1(0.2410)$ & 629 & 7.80 & 6.81 & 8.0 & 0.27 & 0.08 \\
5 & $0(40.00)$ & $0(0.1705)$ & 758 & 5.80 & 5.47 & 7.9 & 0.22 & 0.06 \\
6 & $0(40.00)$ & $0(0.1705)$ & 758 & 5.50 & 5.51 & 8.5 & 0.24 & 0.06 \\
7 & $-1.41(32.95)$ & $0(0.1705)$ & 625 & 7.22 & 6.32 & 10.0 & 0.32 & 0.07 \\
8 & $1.41(47.05)$ & $0(0.1705)$ & 891 & 7.51 & 5.45 & 9.7 & 0.32 & 0.08 \\
9 & $0(40.00)$ & $-1.41(0.0711)$ & 1,913 & 7.10 & 5.48 & 10.4 & 0.33 & 0.08 \\
10 & $0(40.00)$ & $1.41(0.2699)$ & 507 & 6.52 & 4.42 & 9.4 & 0.35 & 0.07 \\
\hline
\end{tabular}

${ }^{\mathrm{a} C} \mathrm{C} / \mathrm{N}$ : carbon to nitrogen molar ratio in the beginning of the experiment;

${ }^{\mathrm{b}} P_{C A}$ : maximum citric acid production;

${ }^{\mathrm{c}} X_{\text {Max }}$ : maximum biomass obtained;

${ }^{\mathrm{d}} R_{C A / I C A}$ : Mass ratio between CA and ICA;

${ }^{\mathrm{e}} Y_{C A / G}$ : Mass yield of CA from glycerol consumed;

${ }^{\mathrm{f}} Q_{C A}$ : Volumetric citric acid productivity.

obtained. In order to verify if in the best condition (Run 2) it was possible to obtain more CA, initial cell concentration was increased and the results are shown in Table 4. Despite the increase in CA production when initial biomass was raised to $2 \mathrm{~g}$ d.w./L, the isocritric acid production was induced. Higher initial cell concentration reduced $\mathrm{CA}$ production probably because this nitrogen concentration was not enough to maintain this amount of biomass.

\subsection{Comparative Analysis of the Results Obtained at Different Stages of Optimization Process}

Table 5 presents the best results obtained at different stages of the optimization of CA production by Yarrowia lipolytica.

From the best result of the FFD to the best result of 


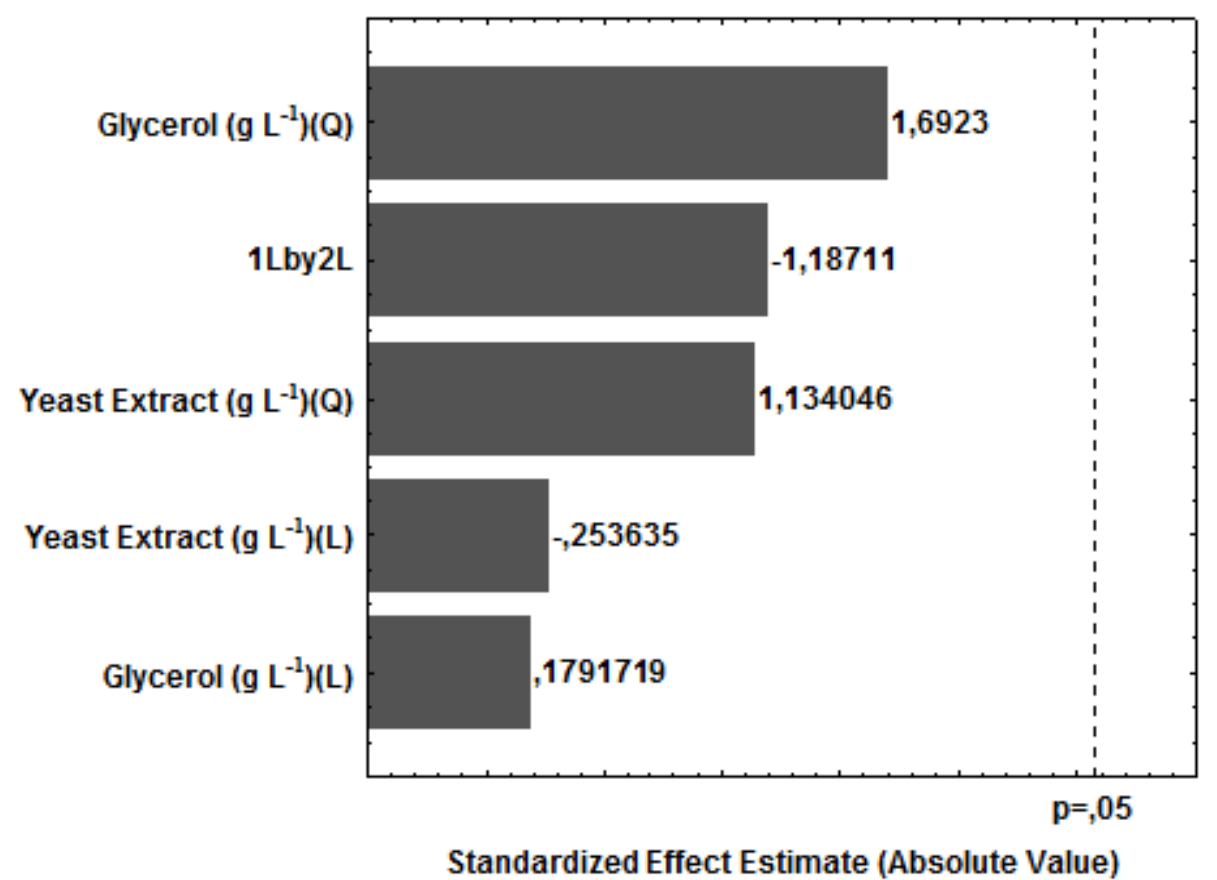

Fig. 5 Pareto diagram for the estimated effect of each variable of the central composite design with crude glycerol. Dependent variable: citric acid production (g/L).

Table 4 Citric acid (CA) production parameters for trials with $45 \mathrm{~g} / \mathrm{L}$ of crude glycerol and $0.1 \mathrm{~g} / \mathrm{L}$ yeast extract with different initial cell concentrations.

\begin{tabular}{lllll}
\hline $\begin{array}{l}\text { Initial cell } \\
\text { concentration } \\
\text { (g d.w./L) }\end{array}$ & $\begin{array}{l}P_{C A}{ }^{a} \\
(\mathrm{~g} / \mathrm{L})\end{array}$ & $R_{C A / I C A}{ }^{\mathrm{b}}$ & $\begin{array}{l}Y_{C A / G}{ }^{\mathrm{c}} \\
(\mathrm{g} / \mathrm{g})\end{array}$ & $\begin{array}{l}Q_{C A}{ }^{\mathrm{d}} \\
(\mathrm{g} /(\mathrm{L} \mathrm{h}))\end{array}$ \\
\hline 1 & 9.22 & 10.36 & 0.41 & 0.10 \\
2 & 10.89 & 4.43 & 0.32 & 0.12 \\
4 & 4.61 & 1.73 & 0.15 & 0.05 \\
6 & 0.96 & - & 0.03 & 0.01 \\
\hline
\end{tabular}

${ }^{\mathrm{a}} P_{C A}:$ maximum citric acid production;

${ }^{\mathrm{b}} R_{C A / I C A}$ : mass ratio between CA and ICA;

${ }^{\mathrm{c}} Y_{C A / G}$ : mass yield of CA from glycerol consumed;

${ }^{\mathrm{d}} Q_{C A}$ : volumetric citric acid productivity.

the CCD with pure glycerol, it was possible to increase CA production in $17 \%$ and to increase the ratio between citric and isocitric acid $\left(R_{C A / I C A}\right)$ in $62 \%$. Biomass production reduced more than $50 \%$ showing the diversion of the carbon flux to CA production.

Substituting pure glycerol for crude glycerol reduced CA production and productivity. The impurities present in crude glycerol may have diverted the metabolic pathway for cell growth, since it increased biomass production 3 times. However, with the experimental design, it was possible to increase CA production $36 \%$ with crude glycerol. This was possible with the increase of $C / N$ ratio, which diverted the carbon flux to CA production (reduction of the biomass production in $30 \%$ ). The ratio between citric and isocitric acids was also increased.

Chatzifragkou et al. [8] have shown that when natural strains of $Y$. lipolytica were cultivated in conical flasks, on media containing crude glycerol in a $C / N$ initial molar ratio of 264, CA obtained was $9.4 \mathrm{~g} / \mathrm{L}$, yielding $0.11 \mathrm{~g}$ of $\mathrm{CA} / \mathrm{g}$ of glycerol consumed. A better result was achieved in the present study $(0.41 \mathrm{~g}$ of $\mathrm{CA} / \mathrm{g}$ of glycerol consumed). Papanikolau et al. $[6,18]$ achieved similar yield $(0.42 \mathrm{~g}$ and $0.40 \mathrm{~g}$ of $\mathrm{CA} / \mathrm{g}$ of glycerol consumed, respectively) and productivity ( $0.14 \mathrm{~g}$ and $0.09 \mathrm{~g}$ of $\mathrm{CA} / \mathrm{L} / \mathrm{h})$ with Yarrowia lipolytica but with higher nitrogen source concentrations (yeast extract: $0.5 \mathrm{~g} / \mathrm{L}$ and ammonium sulphate: $0.5 \mathrm{~g} / \mathrm{L}$ ) than the present study (yeast extract $0.1 \mathrm{~g} / \mathrm{L}$ and no ammonium sulphate). The optimization of CA production in this investigation have also taken into account the reduction of ICA production, which is not often observed in literature and this by-product is a huge problem for the CA separation process. 
Table 5 Comparative analysis of the results obtained at different stages of optimization process.

\begin{tabular}{lllll}
\hline Parameters & FFD pure glycerol & CCD pure glycerol & Test with crude glycerol (Run 8) & CCD crude glycerol \\
\hline$P_{C A}(\mathrm{~g} / \mathrm{L})$ & 14.04 & 16.49 & 6.75 & 9.22 \\
$\left.Q_{C A}(\mathrm{~g} / \mathrm{L} \mathrm{h})\right)$ & 0.15 & 0.17 & 0.07 & 0.10 \\
$Y_{C A / G}(\mathrm{~g} / \mathrm{g})$ & 0.47 & 0.55 & - & 0.41 \\
$Y_{X / G}(\mathrm{~g} / \mathrm{g})$ & 0.04 & 0.04 & - & 0.15 \\
$Y_{C A / X}(\mathrm{~g} / \mathrm{g})$ & 12.65 & 20.87 & 1.39 & 2.65 \\
$X_{\max }(\mathrm{g}$ d.w./L) & 4.44 & 2.15 & 6.30 & 4.34 \\
$C / N$ & 741 & 741 & 1561 \\
$P_{I C A}{ }^{\mathrm{a}}(\mathrm{g} / \mathrm{L})$ & 1260 & 1.37 & 1.58 & 0.89 \\
$R_{C A / I C A}$ & 7.89 & 12.0 & 4.3 & 10.4 \\
Initial pH & 6.89 & 7.06 & 7.24 & 6.35 \\
Final $\mathrm{pH}$ & 4.13 & 4.06 & 4.42 & 3.79 \\
\hline
\end{tabular}

${ }^{\mathrm{a}} P_{I C A}$ : concentration of isocitric acid at time of maximum citric acid production.

\section{Conclusions}

The present study showed that Yarrowia lipolytica IMUFRJ 50682 has the ability to consume pure glycerol and glycerol obtained from biodiesel production without cell growth damage. The use of the experimental design technique was effective in the study of the influence of different variables on process of obtaining of CA. Using this technique, it was possible to achieve the best concentrations of glycerol, yeast extract and agitation to optimize CA production. From the experimental designs, was possible to reduce the amount of glycerol and yeast extract, making the process of obtaining for $\mathrm{CA}$ more economic, and to reduce the main by-product of the process (ICA). The best initial $C / N$ molar ratios achieved were 714 and 1,561 when pure glycerol and crude glycerol were used a carbon sources, respectively, showing the influence of carbon source on the final result.

\section{Acknowledgments}

The authors acknowledge CNPq (Conselho Nacional de Desenvolvimento Científico e Tecnológico) and CAPES (Fundação de Amparo a Pesquisa do Estado de Rio de Janeiro) for financial support and Mr. Carlos Khalil (M.Sc.), Senior Adviser CENPES Petrobras for having kindly provided the glycerol from the biodiesel production.

\section{References}

[1] M. Pazouki, P.A. Felse, J. Sinha, T. Panda, Comparative studies on citric acid production by Aspergillus niger and Candida lipolytica using molasses and glucose, Bioprocess Engineering 22 (2000) 353-361.

[2] T.V. Finogenova, I.G. Morgunov, S.V. Kamzolova, O.G. Chernyavskaya, Organic acid production by the yeast Yarrowia lipolytica: A review of prospects, Applied Biochemistry and Microbiology 41 (2005) 418-425.

[3] A. Rywińska, P. Juszczyk, M. Wojtatowicz, W. Rymowicz, Chemostat study of citric acid production from glycerol by Yarrowia lipolytica, Journal of Biotechnology 152 (2011) 54-57.

[4] P.F.F. Amaral, T.F. Ferreira, G.C. Fontes, M.A.Z. Coelho, Glycerol valorization: New biotechnological routes, Food Bioprod. Process. 87 (2009) 179-186.

[5] M. Sauer, D. Porro, D. Mattanovich, P. Branduardi, Microbial production of organic acids: Expanding the markets, Trends in Biotechnology 26 (2008) 100-108.

[6] S. Papanikolaou, L. Muniglia, I. Chevalot, G. Aggelis, I. Marc, Yarrowia lipolytica as a potential producer of citric acid from raw glycerol, Journal of Applied Microbiology 92 (2002) 737-744.

[7] L.C. Meher, D.V. Sagar, S.N. Naik, Technical aspects of biodiesel production by transesterification: A review, Renewable and Sustainable Energy Reviews 10 (2006) 248-268.

[8] A. Chatzifragkou, A. Makri, A. Belka, S. Bellou, M. Mavrou, M. Mastoridou, et al., Biotechnological conversions of biodiesel derived waste glycerol by yeast and fungal species, Energy 36 (2011) 1097-1108.

[9] G.C. Fontes, N.M. Ramos, P.F.F. Amaral, M. Nele, M.A.Z. Coelho, Renewable resources for biosurfactant production by Yarrowia lipolytica, Brazilian Journal of Chemical Engineering 29 (2012) 483-493. 
[10] P. Fickers, P.H. Benetti, Y. Wache, A. Marty, S. Mauersberger, M.S. Smit, et al., Hydrophobic substrate utilization by the yeast Yarrowia lipolytica, and its potential applications, FEMS Yeast Research 5 (2005) 527-543.

[11] W.E. Levinson, C.P. Kurtzman, T.M. Kuo, Characterization of Yarrowia lipolytica and related species for citric acid production from glycerol, Enzyme and Microbial Technology 41 (2007) 292-295.

[12] W. Rymowicz, A. Rywińska, W. Gladkowski, Simultaneous production of citric acid and erythritol from crude glycerol by Yarrowia lipolytica Wratislavia K1, Chemical Papers 62 (2008) 239-246.

[13] L.V. Silva, R.R. Ribeiro, P.F.F. Amaral, M.A.Z. Coelho, F.L.P. Pessoa, Potential application of raw glycerol from biodiesel in citric acid production by Yarrowia lipolytica, Chemical Engineering Transactions 20 (2010) 211-216.

[14] A.N. Haegler, L.C. Mendonça-Haegler, Yeasts from marine and estuarine waters with different levels of pollution in the state of Rio de Janeiro, Brazil, Applied and Environmental Microbiology 41 (1981) 173-178.

[15] S. Anastassiadis, S. Aivasidis, C. Wandrey, Citric acid production by Candida strains under intracellular nitrogen limitation, Appl. Microbiol. Biotechnol. 60 (2002) 81-87.

[16] A. Rywińska, I. Musiał, W. Rymowicz, B. Żarowska, T. Boruczkowski, Effect of agitation and aeration on the citric acid production by Yarrowia lipolytica grown on glycerol, Preparative Biochemistry and Biotechnology 42 (2012) 279-291.

[17] G. Barth, C. Gaillardin, Physiology and genetics of the dimorphic fungus Yarrowia lipolytica, FEMS Microbiology Reviews 19 (1997) 219-237.

[18] S. Papanikolaou, S. Fakas, M. Fick, I. Chevalot, M.G. Panayotou, M. Komaitis, et al., Biotechnological valorisation of raw glycerol discharged after bio-diesel (fatty acid methyl esters) manufacturing process: Production of 1,3-propanediol, citric acid and single cell oil, Biomass and Bioenergy 32 (2008) 60-71. 